

\title{
Pattern and outcome of Diabetic Ketoacidosis among children with Type 1 Diabetes mellitus at Ile-Ife, Nigeria Elusiyan $\mathrm{JB}^{1,2}$, Kareem $\mathrm{AJ}^{* 2}$, Olorunmoteni $\mathrm{OE}^{1,2}$, Odunlade $\mathrm{OC}^{3}$
}

\author{
${ }^{1}$ Department of Paediatrics and Child Health, Obafemi Awolowo University, Ile-Ife, Nigeria \\ 2 Endocrinology, Metabolism and Neurology Unit, Department Of Paediatrics, Obafemi Awolowo University \\ Teaching Hospitals Complex, Ile-Ife, Nigeria \\ ${ }^{3}$ Department of Paediatrics, Ondo State University of Medical Sciences, Ondo, Nigeria
}

*Correspondence: Dr. AJ Kareem, Department of Paediatrics, Obafemi Awolowo University Teaching Hospitals Complex, Ile-Ife, Nigeria; Email- biodunkareem13@gmail.com; ORCID - https://orcid.org/0000-0002-2565-0881

\begin{abstract}
Background: Diabetic ketoacidosis (DKA) is a life-threatening complication of Diabetes mellitus. There are few reports on the pattern and outcome of DKA in childhood diabetes in Nigeria but none on the diabetic population from Osun State, Nigeria.

Objective: To determine the pattern and factors influencing the outcome of children managed for DKA at the Paediatric Endocrinology Unit of the Obafemi Awolowo University Teaching Hospital Complex (OAUTHC), Ile-Ife, Nigeria, over a ten-year period.

Methods: A retrospective review of the clinical records of all the children managed for Type- 1 Diabetes mellitus (TIDM) over ten years (2007-2016) was done. Relevant information was obtained from the clinical records and the data were analyzed.

Results: A total of 15 children with DKA comprising 8 (53.3\%) males and 7 (46.7\%) females were studied. The male to female ratio was 1.1:1. Twenty-eight episodes of DKA were recorded during the period, thus putting the average frequency per patient at 1.9. DKA was the first manifestation of DM in the majority (86.7\%) of the subjects. The mean age at diagnosis of DM was $11.9 \pm 3.6$ years with about half $(53.3 \%)$ occurring during pre-adolescence. The socioeconomic status of the affected families had an inverse relationship with the frequency of DKA.

Conclusion: DKA is the most common initial presentation of Type-1 DM among Nigerian children, with a high rate of recurrence and an inverse relationship with socioeconomic status.

Keywords: Childhood, Diabetes mellitus, Diabetic ketoacidosis, Outcome.
\end{abstract}

\section{Introduction}

Diabetes mellitus (DM) is a common endocrine and non-communicable disease characterized by chronic hyperglycaemia. [1,2] DM causes disturbances in the metabolism of carbohydrates, fat, and protein due to the deficiency of insulin. Type-1 Diabetes mellitus (T1DM) is the predominant type seen among children. ${ }^{[1]}$ The incidence of T1DM increases by $3 \%$ per year worldwide, ${ }^{[3]}$ the incidence increases with age with an ethnic and racial variation across the globe. ${ }^{[4]} \mathrm{DM}$ is diagnosed in 
the presence of hyperglycaemia, which is defined by the World Health Organization (WHO) as fasting blood glucose greater than or equal to $7 \mathrm{mmol} / 1(126 \mathrm{mg} / \mathrm{dl})$ or random or 2 hours post-prandial blood glucose greater than or equal to $11.1 \mathrm{mmol} / 1(200 \mathrm{mg} / \mathrm{dl})$ coexisting with the symptoms of glycosuria, polyuria, polydipsia, and weight loss. [5]

Diabetic ketoacidosis (DKA) is one of the most severe and life-threatening complications of T1DM. ${ }^{8-10]}$ About $0.5 \%-1 \%$ of children with DKA develop cerebral oedema [9,11] from which $24 \%-28 \%$ death occurs. [9] DKA is the most common initial presentation of DM in most studies $[6,7,13-16]$ reported from Nigeria and Saudi Arabia, [17] contrary to the findings in a report from Kuwait. ${ }^{[18]}$ A study in India ${ }^{[19]}$ reported vomiting and generalized weakness as the most common presenting complaints in DKA and were frequently precipitated by infections and non-compliance with anti-diabetic treatment. [19] Similarly, a Bangladeshi study identified infections as the most common precipitating cause of DKA. [20] In Benin-City, Nigeria, dehydration, and polyuria were the most common presenting features of DKA and is usually precipitated by the omission of insulin doses. [6]

There are few reports on the pattern, presentation and outcome of DKA in the childhood diabetic population in Nigeria [6,7,13-16] and other African countries [21,22] but there has been none from Osun-State, Nigeria. Understanding the pattern and factors involved in DKA occurring as part of T1DM in this environment will provide the advantage of improving knowledge of the disease and thereby, helping with interventions aimed at reducing the number of children with DKA in this centre. Therefore, this study aimed at documenting the pattern, presentation and outcome of DKA in children with T1DM who were managed at the Paediatric Endocrine Unit of the Obafemi Awolowo University Teaching Hospital Complex (OAUTHC), Ile-Ife, OsunState, Nigeria over a ten year period.

\section{Methods}

This is a retrospective review of the hospital records of all the children managed for T1DM at the Paediatric Endocrinology unit of the OAUTHC, Ile- Ife over a ten-year period (January 2007 to December 2016). Ethical approval was obtained from the Obafemi Awolowo University Teaching Hospital Complex Research and Ethics Committee. Relevant data on age at presentation with DKA, age at diagnosis with DM, duration of diabetic illness, frequency of clinic visits, availability of regular supply of insulin, availability of blood glucose monitoring, number and frequency of DKA episodes, family characteristics, outcome of admission and family's socioeconomic status were retrieved and entered into a proforma. The socio-economic status of the families was determined using the Oyedeji method of classification. [23] The social class was determined by combining the highest educational attainment and occupation of the parents, the mean of the four scores (two for the father and two for the mother) to the nearest whole number was the social class assigned to the family. Social classes I and II were considered as the high socio-economic class, social class III was regarded as the middle class while social classes IV and V were considered as low social class.

DKA was defined with the symptoms of ketoacidosis coexisting with biochemical parameters of hyperglycaemia (random blood glucose > 11mmol/L), serum bicarbonate < $15 \mathrm{mmol} / \mathrm{L}$ and ketonuria, according to the International Society for Paediatric and Adolescent Diabetes (ISPAD) and European Society for Paediatric Endocrinology/Lawson 
Wilkins Pediatrics Endocrine Society Consensus. $[8,12]$

The data gathered from the hospital records were analysed using the Statistical Package for Social Sciences for Windows version 20. Descriptive statistics such as frequencies, means, standard deviations, ratios, and percentages were used for all variables while the determinants of frequency and outcome of management of DKA were analysed. The statistical significance level was put at $P$-value $<0.05$.

\section{Results}

A total of 15 children, comprising 8 males $(53.3 \%)$ and 7 females (46.7\%) were included in the study. The male/female ratio was 1.1:1. DKA was the initial presentation in the majority of cases $(13 ; 86.7 \%)$ while $2(13.3 \%)$ initially presented with features such as polyuria, nocturia, polydipsia, and weight loss and later had episodes of DKA. DM was diagnosed at a mean+SD age of $11.9 \pm 3.6$ years with an age range of 7 to 18 years. The Body Mass Index (BMI) of the children ranged from 10.6 to 19.7 $\mathrm{kg} / \mathrm{m}^{2}$ with a mean of $16.5 \pm 2.1 \mathrm{~kg} / \mathrm{m}^{2}$. The other socio-demographic characteristics of the children are shown in Table I with a male predominance (53.3\%) and almost three-quarters of the children were underweight. The majority of the study population $(80.0 \%)$ belonged to the low socioeconomic classes with none in the high socioeconomic class. More than half of the children were diagnosed at the pre-adolescent age.

Table I: Socio-demographic characteristics of the children with DKA

\begin{tabular}{lll}
\hline Variables & Frequency $\mathbf{( n = 1 5 )}$ & Percentage (\%) \\
\hline Sex & 8 & 53.3 \\
Male & 7 & 46.7 \\
Female & & \\
Body Mass Index(kg/m²) & 11 & 73.3 \\
Underweight (<18.0) & 4 & 26.7 \\
Normal weight (18.1-24.9) & 0 & 0.0 \\
Overweight (25-29.9) & & \\
Socioeconomic Status of Parents* & 0.0 \\
High socioeconomic class & 0 & 20.0 \\
Middle socioeconomic class & 3 & 80.0 \\
Low socioeconomic class & 12 & \\
Age at diagnosis of Diabetes & & 53.3 \\
Mellitus (Years) & 8 & 13.3 \\
$<\mathbf{1 2}$ & 2 & 26.7 \\
$\mathbf{1 2 - 1 4}$ & 4 & 6.7 \\
$\mathbf{1 5 - 1 7}$ & 1 & \\
$\mathbf{1 8 - 2 0}$ & & \\
\hline
\end{tabular}

${ }^{*}$ Socioeconomic status was defined using Oyedeji's classification of social class ${ }^{17}$

Table II shows the number of episodes of DKA recorded over the study period. In all, there were 28 episodes putting the average frequency at 1.9 per child. The maximum frequency of DKA per child was 3 , as recorded among 4 $(26.7 \%)$ children, while 6 children $(40.0 \%)$ had 
DKA only once. The time interval of recurrence of episodes of DKA ranged from 4 to 72 months with $20.0 \%$ re-occurring within 4 months and $6.7 \%$ within 72 months. Twelve of the children $(80.0 \%)$ had a glucometer at home but only 3 of them monitored their blood glucose regularly at home. Insulin is often available through donations from Non-Governmental Organizations (NGOs) and staff of the hospital.
Only 3 of the children and their families were able to buy insulin as required whenever the donated insulin was not available. All the children included in the study had a good clinical outcome of DKA management while on admission. Two (13.3\%) of them, died at home after discharge with a history suggestive of recurred DKA.

\section{Table II: Frequency of glucose monitoring habit and diabetic ketoacidosis}

\begin{tabular}{|c|c|c|}
\hline Variables & Frequency $(n=15)$ & Percentage (\%) \\
\hline \multicolumn{3}{|c|}{ Frequency of DKA* } \\
\hline Once & 6 & 40.0 \\
\hline Twice & 5 & 33.3 \\
\hline Thrice & 4 & 26.7 \\
\hline \multicolumn{3}{|c|}{$\begin{array}{l}\text { Interval between occurrence of } \\
\text { DKA* (in months) }\end{array}$} \\
\hline 0 & 6 & 40.0 \\
\hline 4 & 3 & 20.0 \\
\hline 5 & 2 & 13.3 \\
\hline 9 & 1 & 6.7 \\
\hline 12 & 2 & 13.3 \\
\hline 72 & 1 & 6.7 \\
\hline \multicolumn{3}{|c|}{$\begin{array}{l}\text { Availability of glucose monitoring } \\
\text { machine }\end{array}$} \\
\hline Yes & 12 & 80.0 \\
\hline No & 3 & 20.0 \\
\hline \multicolumn{3}{|c|}{$\begin{array}{l}\text { Home monitoring of glucose } \\
(\mathrm{n}=12)\end{array}$} \\
\hline Yes & 3 & 25.0 \\
\hline No & 9 & 75.0 \\
\hline
\end{tabular}

Table III shows the presenting features of DM in the children studied. All (100\%) presented with polyuria, thirteen $(86.7 \%)$ with polydipsia and none presented with convulsion. There was a negative correlation between the number of DKA episodes and the families' socioeconomic status (Table IV). However, there were positive but weak correlations between the number of DKA and home monitoring of glucose and the duration of diagnosis of DM.

\section{Discussion}

Diabetic ketoacidosis (DKA) was the initial presentation in the majority of the subjects in this study, similar to the findings in other studies in Nigeria, [6, 7,13-16] Africa [21,22] and Poland. [24] This has been documented to be due to poor knowledge and awareness of early features of DKA in developing countries unlike in developed countries where children are 
managed in the early stages of the disease before

the

onset

of

DKA.

[25]

Table III: Frequency of Presenting Clinical Features of Diabetes mellitus in the study population

\begin{tabular}{|c|c|c|}
\hline Variables & Frequency $(n=15)$ & Percentage (\%) \\
\hline \multicolumn{3}{|l|}{ Polyuria } \\
\hline Yes & 15 & 100.0 \\
\hline No & 0 & 0.0 \\
\hline \multicolumn{3}{|l|}{ Polydipsia } \\
\hline Yes & 13 & 86.7 \\
\hline No & 2 & 13.3 \\
\hline \multicolumn{3}{|c|}{ Polyphagia } \\
\hline Yes & 3 & 20.0 \\
\hline No & 12 & 80.0 \\
\hline \multicolumn{3}{|c|}{ Difficulty with breathing } \\
\hline Yes & 8 & 53.3 \\
\hline No & 7 & 46.7 \\
\hline \multicolumn{3}{|c|}{ Convulsion } \\
\hline Yes & 0 & 0.0 \\
\hline No & 15 & 100.0 \\
\hline \multicolumn{3}{|c|}{ Loss of consciousness } \\
\hline Yes & 9 & 60.0 \\
\hline No & 6 & 40.0 \\
\hline \multicolumn{3}{|c|}{ Weight loss } \\
\hline Yes & 6 & 40.0 \\
\hline No & 9 & 60.0 \\
\hline \multicolumn{3}{|c|}{ Abdominal pain } \\
\hline Yes & 4 & 26.7 \\
\hline No & 11 & 73.3 \\
\hline \multicolumn{3}{|l|}{ Weakness } \\
\hline Yes & 6 & 40.0 \\
\hline No & 9 & 60.0 \\
\hline \multicolumn{3}{|l|}{ Vomiting } \\
\hline Yes & 2 & 13.3 \\
\hline No & 13 & 86.7 \\
\hline
\end{tabular}

The most frequent clinical features included polyuria and polydipsia, similar to the reports from Kano [16] whereas dehydration and polyuria were reported as the most common features in the Benin study. [6] In India, [19] vomiting and generalized weakness were reported as the major clinical features in children with DKA. This could be that most cases of DM presented on account of polyuria which could present as nocturia or bedwetting. Bedwetting is a major cultural concern in Africa and is often a reason for seeking health care.

The frequency of DKA was more than once in the majority of the children, similar to what was 
reported by Mahesh. [19] This could be attributed to non-compliance with insulin therapy, poor blood glucose control, and monitoring and low socioeconomic situation.

Table IV: Relationship between the number of Diabetic Ketoacidosis and socio-demographics of children

\begin{tabular}{llllll}
\hline Variables & & $\begin{array}{l}\text { Socioeconomic } \\
\text { Status }\end{array}$ & $\begin{array}{l}\text { Home } \\
\text { Monitoring } \\
\text { of } \\
\text { Blood } \\
\text { Glucose }\end{array}$ & $\begin{array}{l}\text { Availability of } \\
\text { Blood } \\
\text { Glucose } \\
\text { monitoring } \\
\text { devices }\end{array}$ & $\begin{array}{l}\text { Duration of diagnosis of } \\
\text { Diabetes mellitus }\end{array}$ \\
\hline $\begin{array}{l}\text { Number of } \\
\text { DKA in } \\
\text { lifetime }\end{array}$ & $\begin{array}{l}\text { Pearson } \\
\text { Correlation }\end{array}$ & -0.522 & 0.184 & -0.154 & 0.437 \\
& $P$ value & 0.046 & & & \\
& $\mathrm{~N}$ & 15 & 0.567 & 0.599 & 0.104 \\
\hline
\end{tabular}

This is corroborated by the fact that only three of the children monitored blood glucose at home despite glucometer being made available to twelve of the children. Most of the children in this study developed DKA once the free insulin given to them finished or was out of stock in the hospital, which might have contributed to the increase in the number of DKA episodes.

It is worthy of note that the majority of the subjects belonged to the low socioeconomic classes with none from the high socioeconomic class. This is contrary to the findings in the studies by Onyiriuka et al [6] and Oyenusi et al [7] who reported that most children belonged to the middle socioeconomic class and a few to the high socioeconomic class in their respective population. The difference could be due to the population studied which is a reflection of the socioeconomic status of the environment. While the study of Onyiriuka et al [6] was done in Benin City, Oyenusi et al [7] studied children in Lagos; both centres are metropolitan and state capital cities when compared to Ile-Ife, Osun-State, a semi-urban town with the majority of the population belonging to the middle and low socioeconomic class. There is an inverse relationship between the socioeconomic class and the frequency of DKA. This might have contributed to the high recurrence rate of DKA.
This is similar to the findings in a study done by Tull et al [26] who reported a higher prevalence of T1DM in children whose parents belonged to the low socioeconomic class. The financial constraint in such families may be responsible for the insufficient supply of insulin and consequently, non-compliance with insulin therapy. It has been suggested that a scale-up of the National Health Insurance Scheme in Nigeria may improve access of affected families to quality care. [27] Similarly, the role of Nongovernmental Organizations such as the Life for a Child Care (LFAC), in making insulin available to indigent patients may reduce the recurrence of DKA. [28]

Most children in the present study were diagnosed with DM in the pre-adolescent age in agreement with previous reports in Nigeria [6,7] and Malta. [29] This is in contrast to the findings in a Polish study by Pawlowicz [30] where the diagnosis was made in adolescence. All the children with DKA in the present study had a good clinical outcome of management. However, two of the children died at home without resorting to the hospital for treatment, probably from episodes of DKA.

The major limitation of this study was the small number of children studied. Although a study 
spanning a four-year period in Kano, Nigeria, reviewed eighteen children, [16] other Nigerian studies [6, 7] reviewed a remarkably larger number of children with DKA. Nevertheless, there is a disparity in the prevalence of T1DM across the African sub-region. [31] The reason for this disparity in prevalence is not as yet very clear. More research is needed to be able to elucidate this. However, it is likely that the documented pattern of DKA among children with T1DM in the study population may not be significantly different were the sample size larger. A multidisciplinary team approach, involving counseling, diabetic education, improved awareness of the possibility of DM in children and appropriate health care - seeking behaviour may reduce the incidence of DKA. This is based on the premise that it may be the initial presentation of T1DM among affected children while the availability of insulin and adequate self, home-based blood glucose monitoring may help reduce the occurrence of DKA.

\section{Conclusion}

DKA is the most common initial presentation of T1DM among children in our unit with a high rate of recurrence among the patients. The frequency of DKA has an inverse relationship with the socio-economic status of the families.

Authors' Contributions: EJB and KAJ conceived and designed the study, did literature review and data analysis and interpretation. All the authors drafted the manuscript and approved the final version of the manuscript.

Conflict of Interest: None.

Funding: Self-funded.

Publication History: Submitted 05 February 2019; Revised 10 April 2019; Accepted 03 June 2019.

\section{References}

1. Frier BM, Truswell AS, Shepherd J, Jung R, Delooy A. Diabetes mellitus, and nutritional and metabolic disorders. In: Haslett C, Edwin RC, John AAH, Nicolas AB (Editors). Davidson's Principle and Practice of Medicine. 18 $8^{\text {th }}$ Ed. Edinburgh. Churchill Livingstone Harcourt; 1999. p 472-514.

2. Patterson CC, Dahlquist GG, Gyurus E, Green A, Soltesz G. Incidence trends for childhood type 1 diabetes in Europe during 1989-2003 and predicted new cases 2005-20: a multicenter prospective registration study. Lancet 2009; 373: 2027-2033.

3. DIAMOND Project Group. Incidence and trends of childhood Type 1 Diabetes worldwide 1990-1999. Diabetes Med 2006; 23: 857-866.

4. Karvonen M, Viik-Kajander M, Moltchanova E, Libman I, LaPorte R, Tuomilehto J, et al. Incidence of childhood type 1 diabetes worldwide. Diabetes Mondiale (DiaMond) Project Group. Diabetes Care 2000; 23: 15161526.

5. World Health Organization. Global Report on Diabetes. Geneva, 2016.

6. Onyiriuka AN, Ifebi E. Ketoacidosis at diagnosis of Type 1 diabetes in children and adolescents: frequency and clinical characteristics. J Diabetes Metab Dis 2013; 12: 47.

7. Oyenusi EE, Nwaogu NTL, Oduwole AO. Ketoacidosis at diagnosis of Type 1 diabetes in children and adolescents in Lagos, SouthWest Nigeria: the pattern over 10 years. African J Diabetes Med 2016; $24: 2$.

8. Wolfsdorf JI, Glaser N, Agus M, Fritsch M, Hanas R, Rewers A, et al. ISPAD clinical practice consensus guidelines 2018: Diabetic ketoacidosis and the hyperglycaemic hyperosmolar state. Pediatric Diabetes 2018; 19: 527. 
9. Bialo SR, Agrawal S, Boney CM, Quintos JB. Rare complications of paediatric diabetic ketoacidosis. World J Diabetes 2015; 6: 167 174.

10. Galler A, Stange T, Muller G. Incidence of diabetes in children aged less than 15 years and its clinical and metabolic characteristics at the time of diagnosis: data from the childhood diabetes registry of Saxony, Germany. Horm Res Paediatr 2010; 74: 285 291.

11. Ghetti S, Lee JK, Sims CE, Demaster DM, Glaser NS. Diabetic ketoacidosis and memory dysfunction in children with Type 1 diabetes. J Pediatr 2010; 156: 109-114.

12. Dunger DB, Sperling MA, Acerini CL, Bohn DJ, Daneman D, Danne TP, et al. European Society for Paediatric Endocrinology/Lawson Wilkins Pediatric Endocrine Society Consensus Statement on diabetic ketoacidosis in children and adolescents. Pediatrics 2004; 113: e133-e140.

13. Jaja T, Yarhere I. The pattern of presentation and trends of childhood diabetes mellitus in Port Harcourt, Southern Nigeria. Brit Med Med Res 2015; 5: 247-253.

14. Ibekwe UM, Ibekwe CR. Pattern of Type 1 diabetes mellitus in Abakaliki, South-eastern Nigeria. Pediatric Oncall J 2011; 8: 59-62.

15. Ugege O, Ibitoye PK, Jiya NM. Childhood diabetes mellitus in Sokoto, north-western Nigeria: a ten-year review. Sahel Med J 2015; 16: 97-101.

16. Umar I. Pattern of presentation of Type 1 diabetic patients in Kano, Nigeria. Niger J Basic Clin Sci 2016; 13: 85-88.

17. Habib HS. Frequency and clinical characteristics of ketoacidosis as onset of childhood type 1 diabetes mellitus in Northwest Saudi Arabia. Saudi Med J 2005; 26: 1936-1939.
18. Abdul-Rasoul M, Al-Mahdi M, Al-Qattan H, Al-Tarkait N, Alkhouly M, Al-Safi R, et al. Ketoacidosis at presentation of type 1 diabetes in children in Kuwait: frequency and clinical characteristics. Pediatr Diabetes 2010; 11: 351-356.

19. Mahesh MG, Rajendra PS, Chandra BJS, Sajed S. The study of the different clinical patterns of Diabetic Ketoacidosis and common precipitating events and independent mortality factors. J Clin Diagn Res 2017; 11(4); 42-46.

20. Ashraf UA, Muhammad AR, Raziar MR, Reshad FN, Khwaja NU. Diabetic ketoacidosis: pattern of precipitating causes. J Enam Med Col 2014; 4: 94-97.

21. Reddy Y, Ganie Y, Pillay K. Characteristics of children presenting with newly diagnosed type 1 diabetes. S Afr J Child Health 2013; 7: 46-48.

22. Majaliwa ES, Munubhi E, Ramaiya K, Mpembeni R, Sanyiwa A, Mohn A, et al. Survey on acute and chronic complications in children and adolescents with type 1 diabetes at Muhimbili National Hospital in Dar es Salaam, Tanzania. Diabetes Care 2007; 10: 2187-2192.

23. Oyedeji GA. Socio-economic and cultural background of hospitalized children in Ilesha. Niger J Paediatr 1985; 12: 111-117.

24. Roche EF, Menon A, Gill D, Hoey H. Clinical presentation of type 1 diabetes. Pediatr Diabetes 2005; 6: 75-78.

25. Lokulo-Sodipe K, Moon RJ, Edge JA, Davies $\mathrm{JH}$. Identifying targets to reduce the incidence of diabetic ketoacidosis at diagnosis of type 1 diabetes in the UK. Arch Dis Child 2014; 99: 438-442.

26. Tull ES, Jordan OW, Simon L, Laws M, Smith PO, et al. Incidence of childhood-onset IDDM in black African-Heritage populations 
in the Caribbean. The Caribbean AfricanHeritage IDDM Study (CAHIS) Group. Diabetes Care 1997; 20: 309-310.

27. Elusiyan JBE, Okeniyi JAO, Adegoke OO. Challenges of managing childhood diabetes mellitus in Nigeria. Niger Endocrin Pract 2008; 2: 111-115.

28. Elusiyan JBE, Anyabolu HC, Odunlade OC, Oke OJ. Challenge of managing endocrine disorders in a resource constraint setting: A report based on two cases. Niger J Health Sci 2015; 14: 72-75.
29. Formosa N, Calleja N, Torpiano J. Incidence and modes of presentation of childhood type 1 diabetes mellitus in Malta between 2006 and 2010. Pediatr Diabetes 2012; 13: 484-488.

30. Pawlowicz M, Birkholz D, Niedzwiecki M, Balcerska A. Difficulties or mistakes in diagnosing type 1 diabetes in childrendemographic factors influencing delayed diagnosis. Pediatr Diabetes 2009; 10: 542-549.

31. Majaliwa ES, Elusiyan JBE, Adesiyun OO, Laigong P, Adeniran KA, Kandi MC, et al. Type 1 diabetes mellitus in African population; epidemiology and management challenges. Acta Biomed 2008; 79: 255-259.

\begin{tabular}{|c|c|}
\hline (cc) (i) (5) & $\begin{array}{c}\text { This is an Open Access document licensed for distribution under the terms and conditions of the Creative } \\
\text { Commons Attribution License (http://creativecommons.org/licenses/by-nc/4.0). This permits unrestricted, } \\
\text { non-commercial use, reproduction and distribution in any medium provided the original source is adequately } \\
\text { cited and credited. }\end{array}$ \\
\hline
\end{tabular}

